\title{
14
}

\section{Understanding and Going Beyond the Regional Policy Paradox: Conceptual Contributions to Studying Socio-Spatial Polarisation in Europe}

\author{
Garri Raagmaa, Erika Nagy, \\ Franziska Görmar and Thilo Lang
}

The goal of this concluding chapter is to shed light on the conceptual value of the book. We discuss the chapters within the framework of the overall conceptual approach linking territorial cohesion and socio-spatial polarisation with the notion of spatial justice and also connect analytical findings with essential policy recommendations, both of which complement each other. Growing social polarisation and economic inequalities unfolding in new forms across various places brought about academic and policy debates on the meanings of 'development', the ways its dimensions (economic, social, cultural, political) are interrelated, and, moreover, on how macro-structural changes are entangled

\author{
G. Raagmaa $(\bowtie)$ \\ University of Tartu, Tartu, Estonia \\ E. Nagy
}

Centre for Economic and Regional Studies,

Hungarian Academy of Sciences (CERS-HAS),

Békéscsaba, Hungary

(C) The Author(s) 2019

T. Lang and F. Görmar (eds.), Regional and Local Development 
with local and regional processes as well as institutional and social contexts (Pike et al. 2017; Storper 2014). This book contributes to discussing socio-spatial inequalities in relation to macro-structural changes from a critical-spatial perspective of the European 'peripheries'-not only adding a new scalar focus for researching spatial unevenness, but also unveiling how power relations of global/financial capitalism are reproduced through institutional practices across scales (yet played out in many different ways within the periphery) and excavating the reasons for the 'system failures' of actual development policies (see Hudson and Pickles; Hadjimichalis; Pósfai and Jelinek in this volume).

Nowadays, when austerity measures and neoliberal policies are imposed by a few member states and a specific European elite influences development in the whole European Union (see Hudson and Pickles as well as Hadjimichalis in this volume), it is more than timely to ask questions going beyond classical economic development. How can we support regional and local development in a way that helps to decrease socio-spatial polarisation? What kinds of policies are needed to offer equal opportunities for similar living conditions and life chances in all areas and across different categories of space? How do we want to live in future?

As these questions show, we do not understand socio-spatial polarisation as a static and unidirectional concept but as a dynamic one (Kühn and Lang 2017) that can be challenged, rejected or even reversed in the long run (Keim 2006; Lang 2013). The so-called peripheries 'do at times have options, which can become game-changers' (Kühn et al. 2016, 13) and the dynamic, procedural and open character of discourses allows not only central actors but peripheral ones to speak and eventually counteract hegemonic discourses with alternative ones. Some chapters in this book

F. Görmar · T. Lang

Leibniz Institute for Regional Geography, Leipzig, Germany

T. Lang

Global and European Studies Institute, University of Leipzig, Leipzig, Germany 
show that actors can regain control over the development of their regions if they are supported by a political framework that does not restrict bottom-up developments but gives appropriate room for manoeuvre (see Graffenberger; Cebotari and Mihály; Plüschke-Altof and Grootens in this volume). Society as a whole has to think about how we want to live in future, whether we just want to set minimum standards for the availability of public services (Kersten et al. 2017) or give every inhabitant of peripheral locations the same opportunities that people have in metropolitan areas. Such approaches could feature an extension of democratic participation at the regional level, regional coalition building, the development of new action strategies in the sense of community-based regionalism, local economic development (see Graffenberger in this volume), or even de-growth aspirations (e.g. Dax and Fischer 2017; Soja 2010, 9).

Dealing with uneven spatial development and growing sociospatial polarisation is a highly debated field in regional policy and spatial science. From a conceptual theoretical viewpoint, we see the main contributions of the book to this debate in a better understanding of five interrelated topics, which we will present in the following sections: (1) the regional policy paradox in the European Union, (2) the historical legacies leading to administrative centralisation trends in Eastern Europe, (3) globalisation and regional industrial restructuring causing further polarisation, (4) the mechanisms that produce inequalities, and (5) the production of inequalities through social practices and discourses. Based on these key topics, we argue for more agency centred research in peripheral contexts, which focuses on how actors, organisations and institutions on multiple scales shape the development of currently peripheralised places. In the final section of this chapter, we will also discuss the methodological and policy related issues linked to such an approach.

\section{The Regional Policy Paradox in the European Union}

This book-a collection of chapters based mainly on fresh empirical studies-discusses how European cohesion policy and Eastern European Countries' (CEE) regional policies have emerged and were 
institutionalised, and how the combination of various public interventions dealt with polarisation processes that have intensified during the last two decades. Several chapters help to better understand a certain paradox: that despite generous regional policies in the European Union-designed to contribute to a decrease in regional disparities-regional polarisation has intensified, especially in Southern, Central and Eastern Europe (Hadjimichalis in this volume). Interestingly, researchers are increasingly working with spatial policies and development themes including the concepts of 'territorial cohesion' and 'spatial justice'. However, these ideals can be achieved apparently less and less (Jones et al. in this volume).

This has undoubtedly challenged geographers, planners and political scientists, giving them the opportunity not only to combine expertise in demography, sociology, political science, classical, new and evolutionary economic geography but also in media studies, ethnography and other disciplines and their methodological armoury. Economic geographers in their own turn have increasingly turned their attention to applied questions of regional development, innovation, socio-spatial inequalities and spatial justice. The financial crisis inspired a shift towards critical approaches that manifested in a growing number of projects grounded in (neo-)Marxism and also in public involvement targeting sociospatial injustice (stemming from neoliberal practices and emerging centralised systems) in CEE in various ways - as was experienced in Margaret Thatcher's United Kingdom. Additionally, political renewal of authoritarian state power in some Visegrad countries accompanied by not only a seeming rise of neoliberal policies but also by nationalist critics towards global capitalism and Brussels provides a rich source of new material to critical geographers.

Up until recently, dominant economic geography theories (such as new economic geography or evolutionary economic geography) and related policy approaches such as growth pole strategies (see Benedek, Varvari, and Litan in this volume) argued that less-favoured, thus peripheralised regions would benefit from knowledge spillovers from and increased connectivity to growing centres. In contrast, recent studies indicate that the hierarchy-reinforcing effects of these features are considerably stronger than the convergence effects (Iammarino et al. 2017, 2). At the same time, critical political economists 
point to the limitations of growth-based development, which are linked to the limited availability of natural resources, a growing focus on personal satisfaction and well-being and new societal challenges, such as recent migration patterns or demographic change processes (Dax and Fischer 2017).

The last 20 years witnessed a shift in the rationale of regional policies from distributive policies to a globally oriented innovation policy putting regional competitiveness at the centre. Transnational corporations (TNC) and global organisations such as the World Bank have greatly impacted public governance to meet the needs of global capital. The prevailing rhetoric suggests that countries, regions and cities compete globally to offer companies the best environments. In parallel with globalisation, and also as its enabling and spurring factor, the 1980s already saw extensive deregulation: areas that used to be under state control (finance, telecom, media) were taken over by TNCs (Dicken 2015), even though they were still supported by their mother countries. In this discursive environment, Central and Eastern European innovation policies were hibernated during the transition period and, later after the accession, formulated following normative EU policies that remained very short-term in their outlook (Loewen and Schulz in this volume).

Cohesion Policy is above all trying to keep the EU economically competitive at the global scale, it is moving away from its traditional goal of promoting spatial cohesion by supporting development at the regional and local levels. (ibid.)

After EU accession, which brought large-scale cohesion and regional policy instruments to Eastern Europe, it would have been logical to see a decrease in regional differences; instead the discrepancies have grown (Finka 2007; Lang 2015). This somewhat paradoxical result can be explained by 'the blend of EU-driven regional policies in national political conventions. This appears to favour an ongoing territorial polarisation towards the large cities, which consequently leads to the peripheralisation of communities disengaged from development competition' (Brad 2018, 142). 
The general change in thinking has inevitably led to territorial restructuring of governance in response to global processes. An important trend in this regard is the emergence of so-called 'soft spaces', which alongside the tactical use of 'fuzzy boundaries' is related to a policy impetus to break away from the shackles of pre-existing working patterns. EU policies have contributed intensively to a breakaway from current administrative structures and to the creation of these soft spaces; they are leading in 'soft planning' (Purkarthofer 2016; Purkarthofer and Mattila 2018; Telle, Špaček, and Crăciun in this volume).

Another trend is the rising impact of EU sectoral regulations. The EU uses numerous directives and policy tools that have impact on territorial governance and spatial development. EU environmental legislation has been the most influential, but many other areas are becoming increasingly operative (Cotella 2017). The norms and regulations dictated from Brussels are frequently 'spatially blind' and may amplify economic problems in peripheries. As Paasi and Metzger $(2017,27)$ formulate it,

The world is much more complex than what can be grasped with the conceptual tools available at any given time.

Concepts that ignore spatial variety and the need for institutional capacity building and fail to involve local actors fall particularly short in CEE (Brad 2018; Loewen 2018; Cebotari and Mihály in this volume). Instead, development policies should be 'solidly grounded in theory and evidence, combining people-based with place-based approaches, and empowering local stakeholders to take greater control of their future' offering the most realistic and viable options for peripheralised regions (Rodríguez-Pose 2018, 206; see also Iammarino et al. 2017). More flexibility seems to be needed to better translate general EU policies to specific national, regional and local conditions. This would also help to introduce locally rooted and distributed policies (Iammarino et al. 2017; Jones et al. in this volume; Küpper et al. 2017) that address all dimensions of regional development alike and do not only focus on the economic realm. 


\section{EU Policies Meeting Historical Legacies: Discrepancies in Administrative Capacities}

Administrative decentralisation and the restoration of pre-war structures occurred in most CEE countries in the 1990s. Small local municipalities struggled to follow global economic processes and, as a result, discrepancies between national cores and peripheral regions increased. This, in turn, forced ministries to centralise services. The concept of new public management spread and CEE national public authorities themselves began to compete: regional and local operations were gradually taken under the direct control of ministries and central agencies, which starkly contrasts with devolution in Western European countries.

By the end of the 1990s, governing practices in CEE countries were affected by Europeanisation processes, and the pressure increased in the 2000s as a result of EU accession and harmonisation with the acquis communautaire. These changes had a far greater impact as CEE countries were not used to such rules and lacked, unlike their Western counterparts, established democracies. The negotiations regarding national and EU policies were mostly done in the interest of getting bureaucracy to function well on both sides. Since the period of negotiations was limited, capacity differences at lower levels in the administrative hierarchy were not taken into account. The commission mainly focused on increasing national level performance (Bachtler et al. 2014), which further increased the discrepancies between national and local/regional capabilities and, in fact, excluded the application of partnership and subsidiary principles.

The European Union tended to choose central governments to distribute pre-joining aid and to implement Structural Funds since it was sceptical of local/regional administrative capacities (Kungla 2007). For the implementation of EU regional development policies, new parallel administrative structures were established. This led to increased fragmentation and weakened the possibility of harmonising policies in CEE. It is evident that re-centralisation and the subordination of spatial planning to sectoral regulations came about under European Commission pressure. Since CEE politicians and officials wanted to optimise the funds 
they could get from the Structural Funds, they agreed to the expectations of Brussels without much objection (ESPON 2017).

Cohesion Policy has shifted in its overall aim from reflecting ideals of regionalisation and integration associated with the Europe of the Regions strategy to competitiveness and growth [...]. In CEE countries, these shifts coincided, firstly, with transition and EU accession, democratic and institutional capacity-building, and extreme underdevelopment of peripheral regions, and secondly with 'catching up', crisis-induced polarisation, political centralisation and regional competition. (Loewen and Schulz in this volume)

Furthermore, parallel spatial strategy processes have been started, so local development officers have been involved in designing a number of different, greatly overlapping local/regional strategy processes: LEADER, coastal fisheries, ERDF measures and county development strategies (see EMoF 2018). The latter received less attention since there have been no definite sources for their implementation. In addition, technical work (strategy and project writing) is usually outsourced to professional firms and these strategies are usually evaluated by city-based ministerial officials and consultants. Thus, capacity building focused mainly on the national level and the dissonance between CEE national and regional/local governance increased. The administrative systems in CEE dealing with EU measures became effective as soon as procedural regulatory and financial obligations were put in place, but had difficulties with programming, project selection as well as the implementation and integration of evaluation feedback (Bachtler et al. 2014). In addition, regions that have long faced serious decline and a loss of human resources are most probably less able to apply for and manage complex projects. As European policies seem to focus more on verifying expenses than on results, this does not yield the expected rise in knowledge and competitiveness, but has created, especially in the still weak CEE civil societies, a rise of quid pro quo (clientelist) relationships and an expansion of a professional 'project class' (Kovách and Kučerová 2006). Increased competition and specific criteria limit the number of potential applicants and strengthen the chances of organisations that are narrowly specialised to consult on certain measures. The consultancy firms that have built Europe-wide networks, including offices in Brussels, 
expand. Moreover, empirical studies suggest that individual Euroregion offices act more as gate-keepers to Structural Funds than as knowledge pools: despite the many cross-border projects that have been set up, information sharing and joint objectives have proven to be very limited and the capacity of public authorities differs greatly (Telle, Špaček and Crăciun in this volume) potentially leading to dysfunctional joint actions (Telle 2017; Špaček 2018).

Thus, it is unsurprising that EU post-accession investments have contributed to great regional differences in CEE countries, while turning convergence, partnership and subsidiarity principles into a farce. For the sake of accountability, the EU designed parallel administrative structures, which have weakened local and regional development capacities in CEE. To avoid or resolve sectoral conflicts, networking between national administrations is enforced, but this widens the gap with lower-level administrations. Generally, this calls for more administrative decentralisation in CEE countries. The cases of Czechia, Estonia, Hungary, Latvia, Slovakia and Romania show that the centralised EU regional policy cannot fulfil its objectives when there is a lack of capacity in localities and regions. Even national regional policy programmes are now too centralised and ultimately favour the development of urban cores (Raagmaa et al. 2014; Brad 2018; ESPON 2017; Loewen 2018; Špaček 2018; Loewen and Schulz in this volume).

Nevertheless, the example given by Nordic countries shows that strengthening local governments and compensating thin organisational density by bolstering and creating cooperative institutions can countervail peripheralisation processes (Isaksen 2001; Trippl et al. 2015).

\section{Globalisation and Regional Industrial Restructuring: Causes for Further Polarisation?}

During the last two decades, we have witnessed a triumph of neoliberal thinking. New narratives about globalisation and metropolisation spread not only among business leaders, but were also actively distributed by scientists (such as new economic geography by 
Krugmann and Venables 1995 and spiky world by Florida 2005) and influential policymakers (such as the new economic geography approach by the World Bank 2009). Sometimes, size has become the only criterion for the competiveness of enterprises, cities and even universities leading to various amalgamation processes in Europe and furthering the increase of regional disparities and spatial injustice.

Hudson and Pickles in their chapter draw parallels with the situation at the turn of the 1970s. There are several common features when comparing this early globalisation phase with CEE restructuring in the 1990s: privatisation, inflow of foreign capital and greenfield investments, takeovers and closedowns, the changing role of trade unions, let alone unemployment, environmental degradation and depopulation of old industries that dominated urban agglomerations. Still, there are also remarkable differences. While Northeast England can be considered a periphery of the UK, whose capital London became the global financial centre, industrial agglomerations in CEE are considered to be peripheries of peripheries and are hardly accessible from the European core. In the 1990s, globalisation and the neoliberal values associated with it were rapidly accepted by the political elites in several CEE countries (but not everywhere)- they wanted to rid themselves of their socialist legacy. During the transition period, so called 'cowboy capitalism' (a hyper-liberal variation of capitalism-see Gersemann 2005) caused massive unemployment, simultaneous collapse of existing social security systems and high crime rates.

Enterprises in CEE were privatised and often taken over by Western companies. Their management concentrated in the capitals; decisionmaking and $R \& D$ operations were moved abroad, whereas the branches in Eastern Europe focused mainly on materials and labour (Woods 2011). At the same time, CEE governments lacked (and still do) the means as well as the rights (due to EU limitations on state aid) to boost local companies. Rising wages led to the closing of 
labour-intensive firms, which has been counterbalanced by asymmetric restructuring and concentration of service jobs into national centres.

In consequence, there is a huge difference between the volume of private $R \& D$ investments in Western and CEE countries. Future cohesion policy reforms need to take this 'innovation gap' into account and acknowledge the different national policy frameworks. So far, regional capacities for innovation-driven growth, such as institutions of higher education or high-tech enterprises, are more developed and more equally territorially distributed in old member states (Telle, Špaček, and Crăciun in this volume).

These observations show that, despite the high human development level in CEE (UNDP 2016), differences in the international division of work have remained. CEE developed from an elite industrial region in the socialist block to a semi-periphery, specialising in labour intensive subcontracting for Western companies. Factories located in peripheries were closed down and nearby settlements lost a major share of their population and housing. This has also directly affected migration patterns within the EU: millions of Eastern Europeans have resettled to (Western-)European metropolises in search for better wages and living conditions leaving their countries' peripheries without skilled workers and entrepreneurs. Moldova for instance lost over $40 \%$ of its total population during its never ending transition. A vicious circle of peripheralisation emerged: youth emigration from secluded rural areas, mining settlements or the former mono-structural industrial regions (Moldovan in this volume) has led to an imbalanced age structure, downsizing of services and less progressive local policy making. Migration processes raised problems not only in peripheral regions but also in central areas of immigration, where neoliberal dualised housing policies-i.e. public support to households and regions with higher wealth and income-left the problem of housing shortage unresolved producing polarisation and marginalisation at various scales simultaneously (Pósfai and Jelinek in this volume). 


\section{$4 \quad$ Understanding the Mechanisms that Produce Inequalities: $(\mathrm{Re})$ Conceptualising Macro-Processes}

Revealing the highly complicated mechanisms that produce sociospatial inequalities has given rise to a need to re-think the political economic approach in current debates, particularly in relation to the recent crisis (Hudson 2015). In consequence, the critical stream of political economy that considers unevenness inherent to capitalism has grown during the last years providing a deeper, more nuanced understanding of socio-spatial processes. In line with this thinking, several authors in this volume (Hudson and Pickles; Hadjimichalis; Pósfai and Jelinek) argue for re-politicising the economic-understanding polarities as the outcome of historically emerged, imbalanced yet dynamically changing power relations, that manifest in centralities/peripheralities in flows of capital, labour, knowledge etc.; moreover, they stress the complexity and interrelatedness of socio-spatial processes that produce unevenness. As Hudson and Pickles put it,

...the analysis and diagnosis of the regional problem of inequality and peripheralisation requires a complex articulation of forms of overdetermination, relationality and context that is both economic, cultural and political. (Hudson and Pickles in this volume)

The critical political economic conceptualisations of socio-spatial unevenness were inspired by the crises of capitalism-i.e. the structural problems of industrial regions in the 1970s and 1980s, the collapse of state socialism, and the 2008/2011 financial crash and economic downturn-which led to clear manifestations of socio-spatial inequalities (Christophers 2015; Hudson and Pickles; Hadjimichalis; Pósfai and Jelinek in this volume). Moreover, the crises also highlighted how macro-processes shape the everyday life and well-being of people making academic explanations available to the layperson and opening up macro-concepts to everyday life, local communities and individual agency 
(see Hadjimichalis; Pósfai and Jelinek; Moldovan in this volume) that should be considered as sources for social and economic recovery as well as for new academic concepts such as spatial justice.

What then are the powerful macro-processes that produced new socio-spatial inequalities and reproduced old ones under the recent crisis and the following recovery in Europe-as put forward by the authors of the book? The institutional context of global capitalism and its operating mechanisms (i.e. financialisation, the rentier economy and the reproduction of dependencies through debts), which unfolded unevenly and spread the risks and effects brought about by the crisis in a highly unequal way among households, places, regions and states, eventually recovered and produced an increasingly polarised system in the last few years (see Hadjimichalis; Pósfai and Jelinek in this volume). Understanding how financialisation got along with centralised control of capital flows, the reinforcement of inequalities and dependencies through uneven (unjust) access to loans and distribution of wealth, and how processes penetrated everyday life (e.g. through housing mortgage loans) elucidated the need for re-defining state policies in terms of goals, scope and spatiality.

Another process fuelling socio-spatial polarisation across Europe is migration (Lang 2011). Yet while it is considered a factor of growth in neoliberal development policies, for critical academic research it is a source of understanding of how everyday life, individual agency and structural processes are entangled and inequalities (re)produced. Thus, commuting 'out' or moving elsewhere is a structural process supporting peripheralisation-shrinking and ageing of the population, resulting in economic decline - and also an individual strategy to cope with such processes (see Moldovan in this issue). Recent migration trends are embedded in global, European and also sub-national divisions of labour but the consequences emerge locally. Thus, rural shrinkage can be understood relationally, linking macro-processes, regional economies, local (community) strategies and individual agencies. Discussing such issues in a CEE/Romanian/rural context, we take hints how national and EU policies are homogenising such spaces, and how limited community power is in such 'multiply peripheralised' places (see also Cebotari and Mihály in this volume). 


\section{$5 \quad$ The Production of Inequalities Through Social Practices and Discourses: The Value Added of Agency Centred Research in a Peripheral Context}

The socio-spatial polarisation and reproduction of peripheralities in Europe inspired research along various theoretical approaches and the reconceptualisation of peripheralisation as a multidimensional, multiscalar process relating to various places and agents simultaneously (PoScoPP 2015). This dynamic and relational understanding of uneven sociospatial processes raised more concern among scholars not only about the spatiality of structural shifts, power and social justice, but also about their varied 'landscape' produced by locally embedded social practices and agencies. Researching socio-spatial inequalities through this lens is a source of knowledge on the struggles, strategies and practices of institutions, firms, individuals and communities that produce different peripheralities, and thus for critiquing the blindness of dominant concepts of regional development when it comes to diversity and local/regional agency (Massey 2004; Hadjimichalis and Hudson 2014; Pike et al. 2017). Moreover, research focused on a peripheral context (Graffenberger; Plüschke-Altof and Grootens; Mihály and Cebotari in this volume) helps not only to understand and re-conceptualise the making of inequalities, but also to re-consider individual and institutional strategies as well as community actions as relevant responses to decline and crisis, which are worth embracing in new, more just policy measures.

Social practices are shaped directly or indirectly by discourses and underlying power relations (see Brad 2018; Hadjimichalis; PlüschkeAltof and Grootens in this volume). Thus, understanding the ways in which terms, notions, definitions are produced discursively and reacted to by various agents in peripheries (and beyond) reveal how the hegemonic values and norms of neoliberal capitalism are produced, translated into policies and practices (while pretending to be politically 'neutral'), and how they penetrate everyday life (re)producing unevenness. 
Institutional practices/agencies and the discursive processes shaping them are drivers reproducing inequalities; yet such processes involve many dimensions and scales/places. While researching the power relations of agents acting at various scales, we also should see how inequalities unfold and are reproduced at particular scales and within particular institutional contexts, as is discussed by Kuus, Loewen and Schulz, as well as Telle, Špaček, and Crăciun in this volume. Analysing the uneven production and flow of expertise related to EU regional policies in transnational discourses, Kuus highlights the methodological problem of giving '.. an analytically rigorous and empirically nuanced account of these processes' (Kuus in this volume), due to the strong national bias of our analytical toolkit. To overcome this, Kuus suggests a flexible, transnational approach to understand economic, political and symbolic peripherality.

Researching inequalities from the periphery through social practices and agency has further empirical, methodological and epistemological lessons. Revealing the institutional (and thereby socio-cultural) aspects of division of labour and changing power relations under global capitalism to get more sophisticated knowledge on uneven development has become mainstream in social geography (Massey 1984; Hudson 2015). (i) The spatial embedding of firms was a lens through which the social relations/practices producing inequalities have been studied since the early 2000s (Coe and Yeung 2015). Yet we still have little knowledge on firms in peripheries, even though firms in peripheries do innovate by overcoming local and regional deficits through networking beyond their local context. Analysing this process, Graffenberger in this volume links the problem of peripheralisation to innovation debates, and discourses on culture, institutions and structural change in economic geography; moreover, he refutes the narrative of periphery as a place of no innovation and highlights the multiple agencies behind it. By doing so, he provides inputs for articulating the specific needs of such firms and places, and argues for more varied state policies from developing ICT infrastructure to support networks of knowledge transfer, and also for considering local firms as agents of change. (ii) Communities are also considered the makers of local processes/spaces, and have become 
a popular subject for academic research in the West; yet the conceptualisation of community agency rested largely on Western experiences, something that should be looked at in light of differences in the potentials and limits of communities in European peripheries (Loewen 2018; Cebotari and Mihály in this book). Analysing CEE community projects, Cebotari and Mihaly stress the centrality of state (municipal) agency, represented by local leaders (mayors), which is not only the result but also a driver of peripheralisation; while it enhances local state capacities, the lack of local social involvement questions the social sustainability of local initiatives, and their potential for further, cumulative change, thereby easing peripherality. Thus, the methodological problem of (not) differentiating between communities and municipalities/local state in EU policy measures hides a deeper problem of power relations: state dominance and lack of empowerment in peripheral localities in CEE. (iii) The individual agency of local people has also been widely discussed challenging structuralist arguments on understanding the mechanisms of uneven development (Massey 1984, 2004), and recently as a source of knowledge on the diversity of local/regional trajectories and a resource for putting places that are lagging behind on a new track (Rodríguez-Pose 2013). Although the potential of local agency such as leadership and image making has gained more attention and positive connotations, studies from CEE peripheries highlight the limits of such connotations. Plüschke-Altof and Grootens argue in their chapter that local leaders struggle with enhanced responsibilities and related risks in rural Estonia-e.g. by 'idealising' their localities while changing their image-but their scope is limited heavily by the structural context of multiple dependencies and the lack of resources. Such conclusions should make scholars wary of articulating ideas, arguments, concepts on structures and agencies that might play out very differently in core/ peripheral/semi-peripheral contexts; e.g. thinking about 'successful' local leadership as a resource for counteracting peripherality, and also as a neoliberal argument that places the socio-spatial consequences of neoliberal policies in the responsibility of local actors. 


\section{Methodology, Positionality and Policy Issues}

In our view, the book contributes to a better understanding of socio-spatial polarisation as a relational, multi-dimensional and multi-scalar concept. This understanding includes processes of peripheralisation and (de-)centralisation, highlighting not only economic but also infrastructural, political as well as social and discursive aspects. The book also provides alternative viewpoints working out (1) the political geographies of spatial injustice, (2) current forms of policy and governance in relation to socio-spatial polarisation, and (3) different approaches to regional and local development. Many chapters in the book are based on interactions (interviews) with local, regional and national politicians and policy makers, companies, NGO leaders and also the general public. This approach explains the functionality and underlying power structures related to dominant normative assumptions, conceptualises what territorial cohesion and spatially just policies actually mean to different stakeholders and, last but not least, understands which role academics and academic concepts can play for the development of local initiatives.

At the moment, it seems that in most cases priority is still given to the economic dimension of regional development and complex problems are simplified to technical questions. In contrast, the normative concept of 'spatial justice' with its holistic approach can add to a more nuanced understanding of regional development and territorial cohesion as it seeks to ensure 'access to and use of resources' for future generations and encourages locally and regionally rooted solutions without neglecting distinctive structural problems (Pike et al. 2007, 1264; see also Jones et al. in this volume).

This book offers a specific epistemic lens for understanding growing socio-spatial inequalities and the diverse and interrelated processes behind it: the authors lived and worked in contexts in which peripheralisation and peripherality are experienced in everyday life. Seeing the 
world from inside places hit by economic decline, powerlessness, social and environmental crisis and seeing how neoliberal capitalism is 'lived' there can be used as sources for motifs to make new claims, arguments and challenge concepts and theories attached to powerful centres of knowledge production. This entanglement of the mundane and the academic in a researcher's work is inspiring, and being constantly aware of it is a source of being reflective, of placing ourselves/our work within academic life and being attached to and arguing for/against existing concepts and theories, as well as to see our work in a 'wider world' in which our projects are seen, critiqued or praised for (not) being beneficial to those who have been researched. Moreover, our reports might have far-reaching effects on socio-spatial processes by supporting various policies. Here we should always keep in mind the developmentroutes/detours, milestones, relations - of our own academic career to relate our work to the 'world out there' (discussed explicitly by Hudson and Pickles in this volume).

Being part of the world in which we work also raised methodological concerns. One key issue pointed out by some authors in this book is the agency of the researcher deeply embedded in the studied field (regions, places, institutions) that might shape the interpretations of local processes and the related actions. Moreover, while doing fieldwork and relying on information from local actors brings about knowledge that is contingent and fluid, reflecting various viewpoints and realities, there is no fast and easy way to grasp the complexity of strategies, practices, relations linked to a place. We need to see the whole picture (always in motion) while understanding individual agencies and their structural contexts (including our own role) (see e.g. Kuus; Plüschke-Altof and Grootens). Revealing the complex relations that produce peripheralities might support moving beyond case studies (that either provide best practices or places of experimentation to achieve them) and getting closer to diverse realities and policies to address community and individual needs that are outside core areas. 


\section{References}

Bachtler, John, Carlos Mendez, and Hildegard Oraže. 2014. "From Conditionality to Europeanization in Central and Eastern Europe: Administrative Performance and Capacity incl. Cohesion Policy." European Planning Studies 22 (4): 735-57. https://doi.org/10.1080/09654313.2013. 772744 .

Brad, Alexandru. 2018. "When Romania Met the Cohesion Policy: Regional Governance Between National Conventions and European Ideals." Administrative Culture 18 (2): 127-48.

Christophers, Brett. 2015. "Geographies of Finance II: Crisis, Space and Political-Economic Transformation.” Progress in Human Geography 39 (2): 205-13. https://doi.org/10.1177/0309132513514343.

Coe, Neil M., and Henry Wai-Chung Yeung. 2015. Global Production Networks: Theorizing Economic Development in an Interconnected World. Oxford: Oxford University Press.

Cotella, Giancarlo. 2017. "How Europe Hits Home? Comparing the Impact of the EU Legislation, Policy and Discourse on Its Member States' Territorial Governance and Spatial Planning Systems.” Warsaw Regional Forum (conference contribution).

Dax, Thomas, and Michael Fischer. 2017. "An Alternative Policy Approach to Rural Development in Regions Facing Population Decline." European Planning Studies 26 (2): 297-315. https://doi.org/10.1080/09654313.201 7.1361596.

Dicken, Peter. 2015. Global Shift: Mapping the Changing Contours of the World Economy. 7th ed. New York: The Guilford Press.

ESPON. 2017. "COMPASS—Comparative Analysis of Territorial Governance and Spatial Planning Systems in Europe." Draft Materials of Estonian, Latvian, Lithuanian, Finnish, Dutch and Slovenian Case Studies. https:// www.espon.eu/planning-systems.

EMoF-Estonian Ministry of Finance. 2018. "Arengu ruumiline ja strateegiline kavandamine, sh regionaaltasandi funktsioonid ruumilise arengu suunamisel.” [Spatial and Strategic Planning of Development, Including Regional Level Functions in the Direction of Spatial Development]. Final Report. Tallinn. https://planeerimine.ee/static/sites/2/arengu-ruumiline-ja-strateegiline-kavandamine.pdf. 
Finka, Maroš. 2007. "Territorial Cohesion-Between Expectations, Disparities and Contradictions." In Territorial Cohesion. German Annual of Spatial Research and Policy 2007, edited by Dietmar Scholich, 23-39. Berlin: Springer.

Florida, Richard. 2005. "The World is Spiky." Atlantic Monthly 10: 48-51.

Gersemann, Olaf. 2005. Cowboy Capitalism: European Myths, American Reality. Washington: Cato Institute.

Hadjimichalis, Costis, and Ray Hudson. 2014. "Contemporary Crisis Across Europe and the Crisis of Regional Development Theories." Regional Studies 48 (1): 208-18. https://doi.org/10.1080/00343404.2013.834044.

Hudson, Ray. 2015. "Uneven Development, Socio-Spatial Polarisation, Political Responses." In Understanding Geographies of Polarization and Peripheralization: Perspectives from Central and Eastern Europe and Beyond, edited by Thilo Lang, Sebastian Henn, Wladimir Sgibnev, and Kornelia Ehrlich, 25-39. New Geographies of Europe. Basingstoke: Palgrave Macmillan.

Iammarino, Simona, Andrés Rodríguez-Pose, and Michael Storper. 2017. "Why Regional Development Matters for Europe's Economic Future." Working Paper 07/2017, Publications Office of the European Union, Luxembourg.

Isaksen, Arne. 2001. "Building Regional Innovation Systems: Is Endogenous Industrial Development Possible in the Global Economy?" Canadian Journal of Regional Science 24 (1): 101-20.

Keim, Karl-Dieter. 2006. "Peripherisierung ländlicher Räume.” Aus Politik und Zeitgeschichte 37: 3-7.

Kersten, Jens, Claudia Neu, and Berthold Vogel. 2017. "Gleichwertige Lebensverhältnisse. Mindeststandards allein genügen nicht." Special Issue Stadtland, Der neue Rurbanismus. Arch + 228: 188-91.

Kovách, Imre, and Eva Kučerová. 2006. "The Project Class in Central Europe: The Czech and Hungarian Cases." Sociologia Ruralis 46 (1): 3-21. https:// doi.org/10.1111/j.1467-9523.2006.00403.x.

Krugman, Paul, and Anthony Venables. 1995. "Globalization and the Inequality of Nations.” The Quarterly Journal of Economics 110 (4): 857-80. Kühn, Manfred, and Thilo Lang. 2017. "Metropolisierung und Peripherisierung in Europa-eine Einführung." Europa Regional 4/2015 (2017): 2-14.

Kühn, Manfred, Matthias Bernt and Laura Colini. 2016. "Power, Politics and Peripheralisation: Two Eastern German Cities." European Urban and Regional Studies 24 (3): 1-16. 
Kungla, Tarvo. 2007. Patterns of Multi-Level Governance in Europe: The Challenge of the EU's Enlargement. Tallinn: Tallinn University of Technology. Küpper, Patrick, Stefan Kundolf, Tobias Mettenberger, and Gesine Tuitjer. 2017. "Rural Regeneration Strategies for Declining Regions: Trade-Off Between Novelty and Practicability." European Planning Studies 26 (2): 229-55. https://doi.org/10.1080/09654313.2017.1361583.

Lang, Thilo. 2011. "Regional Development Issues in Central and Eastern Europe: Shifting Research Agendas from a Focus on Peripheries to Peripheralisation?" In Geography in Visegrad and Neighbour Countries, edited by Agnes Eröss and David Karcsonyi, 57-64. Budapest: Geographical Research Institute HAS.

Lang, Thilo. 2013. "Conceptualizing Urban Shrinkage in East Germany: Understanding Regional Peripheralisation in the Light of Discursive Forms of Region Building." In Peripheralization: The Making of Spatial Dependencies and Social Injustice, edited by Andrea Fischer-Tahir and Matthias Naumann, 224-38. Wiesbaden: Springer.

Lang, Thilo. 2015. "Socio-Economic and Political Responses to Regional Polarisation and Socio-Spatial Peripheralisation in Central and Eastern Europe: A Research Agenda." Hungarian Geographical Bulletin 64 (3): 17185. https://doi.org/10.15201/hungeobull.64.3.2.

Loewen, Bradley. 2018. "From Decentralization to Re-Centralization: Tendencies of Regional Policy and Inequalities in Central and Eastern Europe." Administrative Culture 18 (2): 103-26.

Massey, Doreen. 1984. Spatial Divisions of Labour. London: Macmillan.

Massey, Doreen. 2004. "Uneven Development: Social Change and Spatial Divisions of Labor." In Reading Economic Geography, edited by Trevor J. Barnes, Jamie Peck, Eric Sheppard, and Adam Tickell, 111-25. Oxford: Blackwell.

Paasi, Anssi, and Jonathan Metzger. 2017. "Foregrounding the Region." Regional Studies 51 (1): 19-30. https://doi.org/10.1080/00343404.2016.1 239818.

Pike, Andy, Andrés Rodríguez-Pose, and John Tomaney. 2007. "What Kind of Local and Regional Development and for Whom?” Regional Studies 41 (9): 1253-69. https://doi.org/10.1080/00343400701543355.

Pike, Andy, Andrés Rodríguez-Pose, and John Tomaney. 2017. "Shifting Horizons in Local and Regional Development." Regional Studies 51 (1): 46-57. https://doi.org/10.1080/00343404.2016.1158802. 
Purkarthofer, Eva. 2016. "When Soft Planning and Hard Planning Meet: Conceptualising the Encounter of European, National and Sub-National Planning." European Journal of Spatial Development 61. https://research. aalto.fi/files/4298206/Refereed61.pdf.

Purkarthofer, Eva, and Hanna Mattila. 2018. "Integrating Regional Development and Planning Into 'Spatial Planning' in Finland: The Untapped Potential of the Kainuu Experiment." Administrative Culture 18 (2): 149-74.

PoSCoPP-Research Group Production of Space in the Context of Polarization and Peripheralization. 2015. "Understanding New Geographies of Central and Eastern Europe." In Understanding Geographies of Polarization and Peripheralization. Perspectives from Central and Eastern Europe and Beyond, edited by Thilo Lang, Sebastian Henn, Wladimir Sgibnev, and Kornelia Ehrlich, 1-21. New Geographies of Europe. Basingstoke: Palgrave Macmillan.

Raagmaa, Garri, Tarmo Kalvet, and Ragne Kasesalu. 2014. "Europeanization and De-Europeanization of Estonian Regional Policy." European Planning Studies 22 (4): 775-95. https://doi.org/10.1080/09654313.2013.772754.

Rodríguez-Pose, Andrés. 2013. "Do Institutions Matter for Regional Development?” Regional Studies 47 (7): 1034-47. https://doi.org/10.1080 /00343404.2012.748978.

Rodríguez-Pose, Andres. 2018. "The Revenge of the Places That Don't Matter (And What to Do About It)." Cambridge Journal of Regions, Economy and Society 11 (1): 189-209. https://doi.org/10.1093/cjres/rsx024.

Soja, Edward. 2010. Seeking Spatial Justice. Minneapolis: University of Minnesota Press.

Špaček, Martin. 2018. "Multilevel Cross-Border Governance in the CzechSaxon Borderland: Working Together or in Parallel?" Administrative Culture 18 (2): 175-202.

Storper, Michael. 2014. "Keys to the City: How Economics, Institutions, Social Interaction, and Politics Shape Development." Berkeley Planning Journal 27: 122-24.

Telle, Stefan. 2017. "An Institutionalist View on Experimentalist Governance: Local-Level Obstacles to Policy-Learning in European Union Cohesion Policy." European Journal of Spatial Development 66. http://urn.kb.se/ resolve?urn=urn:nbn:se:norden:org:diva-5045.

The World Bank. 2009. "Reshaping Economic Geography.” World Development Report. http://documents.worldbank.org/curated/en/730971468139804495/ pdf/437380REVISED01BLIC1097808213760720.pdf. 
Trippl, Michaela, Björn Asheim, and Johan Miorner. 2015. "Identification of Regions with Less Developed Research and Innovation Systems." Papers in Innovation Studies No. 2015/1. Lund University: CIRCLE-Center for Innovation, Research and Competences in the Learning Economy. http:// wp.circle.lu.se/upload/CIRCLE/workingpapers/201536_Asheim_et_al.pdf. UNDP. 2016. "Human Development Report 2016." United Nations Development Programme. http://hdr.undp.org/sites/default/files/2016_ human_development_report.pdf.

Woods, Michael. 2011. "Regions Engaging Globalization: A Typology of Regional Responses in Rural Europe." Paper Presented to the AngloAmerican-Canadian Rural Geographers Quadrennial Conference, Manitoba, July 2011. http://www.derreg.eu/system/files/Regions\%20 Engaging\%20Globalization.pdf.

Open Access This chapter is licensed under the terms of the Creative Commons Attribution 4.0 International License (http://creativecommons. org/licenses/by/4.0/), which permits use, sharing, adaptation, distribution and reproduction in any medium or format, as long as you give appropriate credit to the original author(s) and the source, provide a link to the Creative Commons license and indicate if changes were made.

The images or other third party material in this chapter are included in the chapter's Creative Commons license, unless indicated otherwise in a credit line to the material. If material is not included in the chapter's Creative Commons license and your intended use is not permitted by statutory regulation or exceeds the permitted use, you will need to obtain permission directly from the copyright holder.

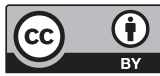

